\title{
Biochemical phenotypes of enteropathogenic Escherichia coli common to Iran and Sweden
}

\author{
M. KATOULI*, I. KÜHN*† and R. MÖLLBY* \\ *Department of Bacteriology, Karolinska Institute, S-10401 Stockholm, and †Department of Bacteriology, The National \\ Bacteriological Laboratory, S-105 21 Stockholm, Sweden
}

\begin{abstract}
Summary. A collection of 143 strains of enteropathogenic Escherichia coli (EPEC) of 11 different serogroups isolated from children with diarrhoea, 71 in Sweden and 72 in Iran, was tested for similarity with a computerised biochemical fingerprinting method. From Sweden, there were 54 different phenotypes, 42 consisting of a single strain and 12 (common phenotypes) containing more than one isolate. From Iran, there were 48 different phenotypes, 38 with only one strain and 10 with more than one. Many of the strains which were biochemically similar, in both countries, also had similar virulence factors. Nine Swedish and 20 Iranian isolates showed biochemical identity to at least one of the strains of the other country, most of them belonging to serogroups $\mathrm{O} 55, \mathrm{O} 119, \mathrm{O} 126, \mathrm{O} 127$ and $\mathrm{O} 128$. The value of the biochemical fingerprinting method as an epidemiological tool and its ability to evaluate clonal relations among $E$. coli strains in different geographical areas is discussed.
\end{abstract}

\section{Introduction}

The term enteropathogenic Escherichia coli (EPEC) was first used by Neter ${ }^{1}$ for serotypes of $E$. coli that were epidemiologically associated with outbreaks of diarrhoea in infants and young children. This term is currently used to denote serotypes of $E$. coli that cause diarrhoea, but the mechanism by which they elicit the disease is unclear. These strains do not produce enterotoxins and are not invasive by the Sereny test. ${ }^{2}$ Several $\mathrm{H}$ types exist within each $\mathrm{O}$ group, and it has been shown that strains of each individual serotype, regardless of their geographical origin, not only share $\mathrm{O}$ and $\mathrm{H}$ antigens but often have common fimbrial antigens and similar outer-membrane-protein (OMP) patterns. ${ }^{3}$ Furthermore, each such $\mathrm{O}: \mathrm{H}$ serotype is associated with a specific and often characteristic biotype, making it possible to predict the biotype from the O:H type and vice versa, without considering the geographical origin of the isolates. ${ }^{4}$ These findings suggest that each bio/serotype of $E$. coli may represent a clone derived from a common progenitor. ${ }^{5}$

Although $O$ antigen typing of $E$. coli strains can be done easily by testing a boiled suspension of bacteria with commercially available antisera, subdivision of the species for epidemiological studies requires complete serological typing of $\mathrm{O}, \mathrm{K}$ and $\mathrm{H}$ antigens; though this gives good differentiation, it is laborious and time consuming and is performed in only a few laboratories. Biotyping of E. coli ${ }^{6}$ with simple tests

Received 4 Sep. 1990; revised version accepted 25 Feb. 1991 has been widely used, alone and in combination with serotyping. ${ }^{5,7}$

In the present study we used a computerised biochemical fingerprinting method to investigate the presence of common biochemical phenotypes among different serogroups of EPEC strains from two geographically different areas. We also evaluated the presence of three potential virulence factors of EPEC strains within the common phenotypes: EPEC adhesive factor (EAF), verocytotoxin (VT) and haemolysin (HLY).

\section{Materials and methods}

\section{Strains of EPEC}

A random selection of 143 EPEC strains from children with diarrhoea were tested: 71 had been isolated in Sweden in 1982-1988, and 72 in Iran in 1985-1988. The Swedish strains were obtained from the National Bacteriological Laboratory (NBL), Stockholm; they had been tested for $\mathrm{O}$ antigen with polyvalent and monovalent antisera (NBL, Stockholm), and had been stored at $-70^{\circ} \mathrm{C}$. The Iranian strains were obtained from the collection of the Pasteur Institute of Iran, Tehran; they had been tested for $\mathrm{O}$ antigen with Difco polyvalent and monovalent antisera, and had been stored in deep agar at room temperature. $\mathrm{K}$ and $\mathrm{H}$ antigens had not been determined for either group. The number and distribution of the strains within each serogroup for both countries are given in table $\mathrm{I}$. 


\section{Biochemical fingerprinting}

A computerised fingerprinting method was used for testing biochemical reactions of the bacteria, ${ }^{8,9}$ by measuring the kinetics of 24 biochemical (fermentation) reactions, chosen to give a high degree of discrimination among E. coli strains (D-xylose, maltose, lactose, sorbitol, rhamnose, L-fucose, glycerol, melibiose, deoxyribose, sucrose, raffinose, sorbose, tagatose, D-arabitol, adenitol, dulcitol, ornithine, 5ketogluconate, melbionate, arbutin, D-arabinose, $\beta$ methyl glucoside, lactulose, cellobiose). The results of four readings of these reactions at different time intervals were used to calculate the similarity coefficients between the tested strains. The coefficients were then clustered to yield a dendrogram.

E. coli strains were incubated overnight on MacConkey agar at $37^{\circ} \mathrm{C}$, and a single colony was subcultured on nutrient agar. The growth was suspended in $8 \mathrm{ml}$ of a medium containing Proteose Peptone (Difco) $0.1 \% \mathrm{w} / \mathrm{v}$ and bromothymol blue $0.01 \% \mathrm{w} / \mathrm{v}$ as indicator, to give a concentration of (25) $\times 10^{8}$ cells $/ \mathrm{ml} ; 150-\mu \mathrm{l}$ volumes of these suspensions were inoculated into the wells of the prefabricated microplates containing four sets of 24 dehydrated reagents (Phene Plate System, BioSys Inova, Stockholm), with a multi-channel pipette. The plates were kept at $4^{\circ} \mathrm{C}$ overnight and incubated at $37^{\circ} \mathrm{C}$ the next morning. The $A_{620}$ of each reaction was read after 4 , 7,24 and $48 \mathrm{~h}$ with a microtitration plate reader (Titertek Multiskan, Flow Laboratories) connected to a microcomputer (Victor-V286C). The similarities between all tested strains were calculated as correlation coefficients (r) as described previously, ${ }^{8,9}$ and clustered according to the unweighted pair group method with arithmetic averages (UPGMA). ${ }^{10}$

From the reproducibility of the method with 50 strains tested in duplicate, an identity level of 0.975 was chosen (mean r-2 SD; 95\% confidence level). Strains with $r$ values higher than this were regarded as identical, and were assigned to the same biochemical phenotype. Phenotypes with more than one isolate were designated $\mathrm{C}$-phenotypes (common phenotypes), and those with only one isolate were designated Sphenotypes (single phenotypes). ${ }^{11}$ Capital letters were used for Swedish C-phenotypes, and small letters for Iranian C-phenotypes (table I).

Homogeneities in the bacterial populations were calculated in two ways: $\overline{\mathbf{r}}_{1}$ is the mean of correlation coefficients between all isolates in each $\mathrm{O}$-group from one country, and $\bar{r}_{2}$ is the mean for all isolates of each O-group from both countries.

\section{Tests for virulence factors}

Adhesion. The presence of EAF was assessed by testing the ability of the bacteria to colonise HeLa cells, as described by Scaletsky et al. ${ }^{12} \mathrm{HeLa}$ cells were grown in $\mathrm{CO}_{2} 5 \%$ at $37^{\circ} \mathrm{C}$ in medium 199 with Earles salts, supplemented with penicillin $100 \mathrm{U} / \mathrm{ml}$, strep- tomycin $100 \mu \mathrm{g} / \mathrm{ml}, 2 \mathrm{mM}$ glutamine and fetal bovine serum $10 \%$. A $1-\mathrm{ml}$ volume of $10^{5}$ cells $/ \mathrm{ml}$ in growth medium was placed in 24-well (16 mm diameter) tissue-culture dishes (Flow Laboratories, Irvine, Scotland) covered with sterile $13-\mathrm{mm}$ coverslips. To each well was added $25 \mu \mathrm{l}$ of bacterial culture, grown in Tryptic Soy Broth (TSB; Difco) at $37^{\circ} \mathrm{C}$ overnight; and plates were incubated for $30 \mathrm{~min}$ at $37^{\circ} \mathrm{C}$ in $\mathrm{CO}_{2}$ $5 \%$. Plates were then washed six times with sterile phosphate-buffered saline $\mathrm{pH} \mathrm{7.2} \mathrm{(PBS)} \mathrm{and} \mathrm{were}$ refilled with the growth medium and incubated for $3 \mathrm{~h}$. Cells were then washed three times with PBS, fixed with methanol, stained with undiluted MayGrünwald stain $(5 \mathrm{~min})$ and Giemsa stain 1 in 20 $(15 \mathrm{~min})$ and rinsed with PBS. Cover slips were removed to microscope slides, dried in the air and observed by light microscopy. Attachment of the bacteria to HeLa cells as a cluster or microcolony was designated localised adhesion (LA) whereas attachment over the entire surface of the cells was designated diffuse adhesion (DA). ${ }^{12}$ To study the possibility of mannose-sensitive adhesion, due to the expression of type 1 (common) pili, all tests were done in duplicate, in the presence and absence of D-mannose $1 \%$ in the growth medium.

$V T$ assay. Filtrates of lysed bacteria were prepared by the method of Baloda et al. ${ }^{13}$ Confluent Vero cell monolayers were obtained in 96-well microtitration plates incubated for 3 days at $37^{\circ} \mathrm{C}$ in $\mathrm{CO}_{2} 5 \%$, each well containing $250 \mu \mathrm{l}$ of medium 199 with Eagle salts, supplemented with fetal calf serum $10 \%$. The growth medium was substituted with fresh medium containing fetal calf serum $2 \%, 25 \mu \mathrm{l}$ of bacterial culture filtrates were added, and the plates were incubated for $24 \mathrm{~h}$ at $37^{\circ} \mathrm{C}$ in $\mathrm{CO}_{2} 5 \%$. Cells were then examined for cytopathic effect, ${ }^{14}$ all tests being done in duplicate. Filtrate of a TSB culture of E. coli O157:H7 (VT +, HLY +) was used as positive control; PBS and TSB were used as negative controls.

$H L Y$ production. Defibrinated sheep blood was washed three times with $0.01 \mathrm{M}$ Tris chloride buffer, $\mathrm{pH} 7 \cdot 5$, containing $0 \cdot 135 \mathrm{M} \mathrm{NaCl}$, and the erythrocytes were added to Blood Agar Base No. 2 (Oxoid) at a final concentration of $5 \%$. Plates of this medium were inoculated with EPEC and examined for haemolysis after overnight incubation at $37^{\circ} \mathrm{C}$.

\section{Results}

\section{Swedish isolates}

Among the 71 Swedish isolates, 12 common (C) phenotypes, containing 2-4 strains each, and 42 single (S) phenotypes were identified. Strains of C-phenotypes belonged to serogroups $\mathrm{O} 26, \mathrm{O} 44, \mathrm{O} 55, \mathrm{O} 111$, O114, O119, O125, O126 and O127 (table I). More than one biochemical phenotype were observed within serogroups $\mathrm{O} 44, \mathrm{O} 55$ and $\mathrm{O} 126$. The two C-phenotypes in group O44 (phenotypes $B_{1}$ and $B_{2}$ ) were closely 


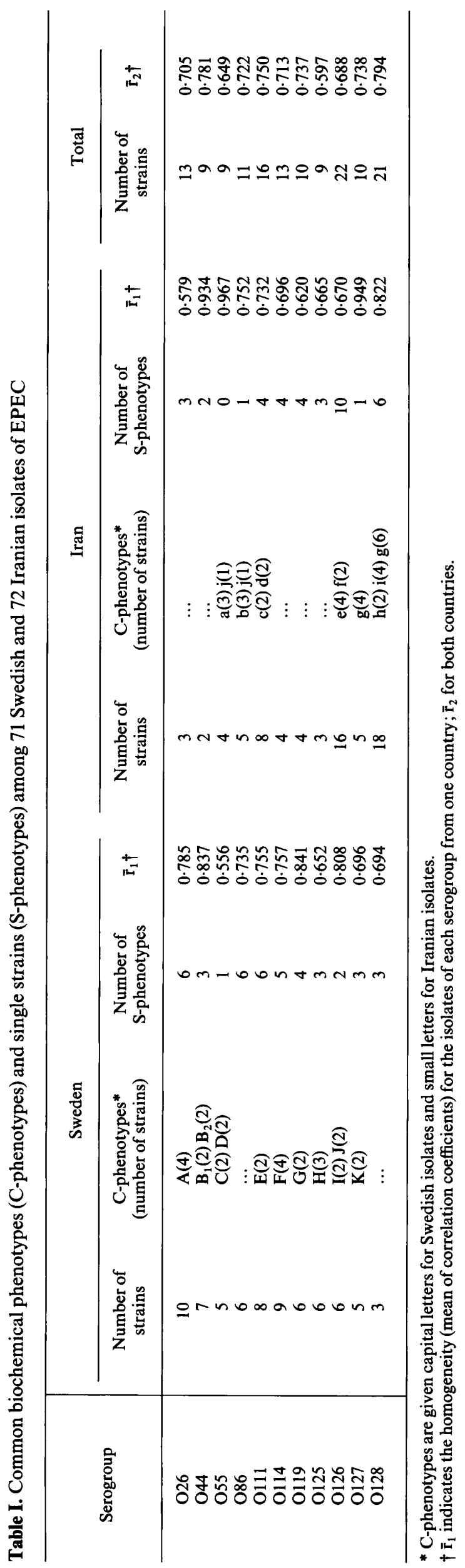


related to each other (similarity level 0.965 ): phenotype $B_{2}$ had slower rates of fermentation of dulcitol, Darabinose and lactulose than those of $B_{1}$. The $C$ phenotypes within groups O55 (phenotypes C and D) and 0126 (phenotypes $I$ and J) were unrelated. Duplicate assays of VT production by the Swedish isolates showed no discrepancies: seven strains were VT producers, six of them being of C-phenotype A, D or E (table II). Mannose-sensitive adhesion (MSA) to HeLa cells was shown by 34 strains $(48 \%)$ : LA with 17 strains, DA with 14 strains, both patterns (LA/DA) with three strains. Of these, 33 strains also showed mannose-resistant adhesion (MRA) and 20 of them belonged to $10 \mathrm{C}$-phenotypes (table II). Only seven strains produced HLY, and all of them belonged to Cphenotype $\mathrm{A}, \mathrm{B}_{2}$ or D (table II).

\section{Iranian isolates}

Among the 72 Iranian isolates, $10 \mathrm{C}$-phenotypes, containing 2-10 strains each, and 38 S-phenotypes were identified. Strains of C-phenotypes belonged to serogroups O55, O86, O111, O126, O127 and O128 (table I), some serogroups containing more than one phenotype, e.g., serogroups O111 (phenotypes c and d), O126 (phenotypes e and f) and O128 (phenotypes h, $\mathrm{i}$ and $\mathrm{g}$ ). C-phenotype $\mathrm{g}$ also contained four strains of group $\mathrm{O} 127$; and two isolates belonging to groups O55 and O86 were both of C-phenotype $\mathrm{j}$ (table I). Five VT producers and four HLY producers were of C-phenotype a, c, d or g (table III). MSA to HeLa cells was shown by 30 strains $(42 \%)$ : LA with 20 strains, DA with nine strains, LA/DA with one strain. Of these, 28 strains also showed MRA and 21 belonged to nine C-phenotypes (table III).

\section{Comparison of Swedish and Iranian isolates}

The total of 143 isolates could be allocated to 96 different phenotypes, of which 20 were common phenotypes consisting of $2-13$ isolates each, and the other 76 were single isolates. The figure shows a dendrogram derived from an UPGMA clustering of the 20 common phenotypes.

Nine Swedish isolates (three C-phenotypes and three single isolates) and 20 Iranian isolates (four Cphenotypes and one single isolate) showed identity to at least one of the isolates of the other country. Most of these strains were of serogroup O55, O119, O126, $\mathrm{O} 127$ or $\mathrm{O} 128$ (figure). Two Iranian strains of groups O55 and O86 (C-phenotype j), and one Swedish strain of group $\mathrm{O} 126$ were identical in biochemical phenotype. The most common phenotype in the whole material contained 13 isolates: two Swedish strains of

Table II. Virulence factors of common biochemical phenotypes (C-phenotypes) among 71 strains of EPEC from Sweden

\begin{tabular}{|c|c|c|c|c|c|c|}
\hline $\begin{array}{l}\text { Strain } \\
\text { no. }\end{array}$ & $\begin{array}{l}\text { Year of } \\
\text { isolation }\end{array}$ & Serogroup & C-phenotype & $\begin{array}{c}\text { MRA } \\
\text { HeLa cell } \\
\text { adhesion }\end{array}$ & $\begin{array}{l}\text { Verotoxin } \\
\text { production }\end{array}$ & $\begin{array}{l}\text { Haemolysin } \\
\text { production }\end{array}$ \\
\hline $\mathrm{C} 154$ & 1987 & $\mathrm{O} 26$ & A & - & + & + \\
\hline $\mathrm{C} 140$ & 1988 & & & - & + & + \\
\hline $\mathrm{Cl}$ & 1988 & & & - & + & + \\
\hline $\mathrm{C} 125$ & 1988 & & & - & + & - \\
\hline $\mathrm{C} 144$ & 1987 & O44 & B1 & DA & - & - \\
\hline E199c & 1982 & & & - & - & - \\
\hline C139 & 1987 & $\mathrm{O} 44$ & B2 & LA & - & + \\
\hline C146 & 1986 & & & LA & - & + \\
\hline $\mathrm{C} 183$ & 1988 & O55 & $\mathrm{C}$ & LA & - & - \\
\hline $\mathrm{C} 100$ & 1987 & & & LA & - & - \\
\hline C135 & 1987 & O55 & D & - & + & + \\
\hline C124 & 1987 & & & - & - & + \\
\hline $\mathrm{C} 106$ & 1987 & 0111 & $\mathbf{E}$ & LA & - & - \\
\hline $\mathrm{Cl13}$ & 1987 & & & LA & + & - \\
\hline $\mathrm{C} 48$ & 1987 & O114 & $\mathrm{F}$ & LA & - & - \\
\hline RS381B & 1983 & & & LA & - & - \\
\hline RS424S & 1983 & & & LA & - & - \\
\hline $\mathrm{C} 606$ & 1987 & & & LA & - & - \\
\hline $\mathrm{C} 279$ & 1986 & 0119 & G & LA/DA & - & - \\
\hline C6 & 1987 & & & - & - & - \\
\hline $\mathrm{C} 120$ & 1987 & $\mathrm{O} 125$ & $\mathbf{H}$ & - & - & - \\
\hline C156 & 1986 & & & LA & - & - \\
\hline $\mathrm{C} 190$ & 1988 & & & LA & - & - \\
\hline $\mathrm{C} 220$ & 1985 & 0126 & I & LA & - & - \\
\hline $\mathrm{C} 241$ & 1985 & & & LA & - & - \\
\hline $\mathrm{C} 274$ & 1984 & 0126 & $\mathbf{J}$ & LA & - & - \\
\hline $\mathrm{Cl} 78$ & 1988 & & & LA & - & - \\
\hline C199 & 1986 & O127 & $\mathbf{K}$ & LA/DA & - & - \\
\hline C 197 & 1986 & & & LA/DA & - & - \\
\hline
\end{tabular}


Table III. Virulence factors of common biochemical phenotypes (C-phenotypes) among 72 strains of EPEC from Iran

\begin{tabular}{|c|c|c|c|c|c|c|}
\hline $\begin{array}{l}\text { Strain } \\
\text { no. }\end{array}$ & $\begin{array}{l}\text { Year of } \\
\text { isolation }\end{array}$ & Serogroup & C-phenotype & $\begin{array}{c}\text { MRA } \\
\text { HeLa cell } \\
\text { adhesion }\end{array}$ & $\begin{array}{l}\text { Verotoxin } \\
\text { production }\end{array}$ & $\begin{array}{l}\text { Haemolysin } \\
\text { production }\end{array}$ \\
\hline 57 & 1985 & O55 & a & LA & - & - \\
\hline 1822 & 1987 & & & LA & - & - \\
\hline 6678 & 1987 & & & - & + & + \\
\hline 2125 & 1985 & 086 & b & - & - & - \\
\hline 2249 & 1987 & & & DA & - & - \\
\hline 3845 & 1988 & & & LA & - & - \\
\hline 2530 & 1987 & O111 & c & - & + & - \\
\hline 3542 & 1987 & & & - & + & + \\
\hline 1114 & 1987 & O111 & d & LA & - & + \\
\hline 2216 & 1987 & & & - & + & + \\
\hline 3441 & 1985 & 0126 & $\mathbf{e}$ & LA & - & - \\
\hline 3643 & 1985 & & & LA & - & - \\
\hline 4958 & 1988 & & & LA & - & - \\
\hline 5160 & 1986 & & & - & - & - \\
\hline 4033 & 1985 & 0126 & $\mathrm{f}$ & LA & - & - \\
\hline 5143 & 1985 & & & LA & - & - \\
\hline 1317 & 1985 & $\mathrm{O} 127$ & g & LA & - & - \\
\hline 1923 & 1985 & & & LA & - & - \\
\hline 2835 & 1985 & & & LA & - & - \\
\hline 1915 & 1988 & & & - & + & - \\
\hline 4655 & 1986 & $\mathrm{O} 128$ & $\mathrm{~h}$ & - & - & - \\
\hline 5564 & 1988 & & & LA & - & - \\
\hline 1620 & 1985 & O128 & $\mathrm{i}$ & - & - & - \\
\hline 5362 & 1985 & & & - & - & - \\
\hline 6172 & 1985 & & & LA & - & - \\
\hline 6779 & 1987 & & & - & - & - \\
\hline 2328 & 1988 & O128 & g & LA & - & - \\
\hline 5666 & 1987 & & & - & - & - \\
\hline 3744 & 1988 & & & - & - & - \\
\hline 4553 & 1985 & & & LA/DA & - & - \\
\hline 6467 & 1986 & & & LA & - & - \\
\hline 2024 & 1986 & & & LA & - & - \\
\hline 2093 & 1986 & O55 & $\mathrm{j}$ & LA & - & - \\
\hline 4173 & 1987 & O86 & & LA & - & - \\
\hline
\end{tabular}

LA, localised adhesion; DA, diffuse adhesion; LA/DA, both types.

C-phenotype K (group O127), 10 Iranian strains of Cphenotype g (groups O127 and O128) and one Swedish S-phenotype of group $\mathrm{O} 128$ (figure).

\section{Discussion}

Different typing systems have been used to investigate the clonal relations between bacteria in epidemiological studies. ${ }^{15-17}$ Major problems with most systems are that all the strains are not typable with one system, or the system is complex and laborious and cannot be used in many laboratories. Furthermore, most of these methods are based only on the establishment of identity or non-identity of the tested strains, and cannot detect possible relations between the isolates. With computerised biochemical fingerprinting, we detected 54 phenotypes among 71 randomly selected EPEC strains from Sweden, and also 48 phenotypes among 72 presumably unrelated strains from Iran. Most strains within each Cphenotype, in both countries, carried the same $O$ antigen and some of them had similar virulence properties.
The presence of a large number of biochemical phenotypes among Swedish and Iranian isolates (54 and 48 , respectively) is not surprising, because biochemical reactions among $E$. coli strains vary widely. However, biochemical identity in this study was set at a similarity level of 0.975 , based on the reproducibility of the system. Therefore, strains that were biochemically very similar to each other, but fell below this identity level, were assigned to different phenotypes. Moreover, some of the strains which were closely related to C-phenotypes, carried the same $\mathrm{O}$ antigen and had similar virulence factors; for instance, the four strains of group $\mathrm{O} 26$ belonging to C-phenotype A were very similar to another Swedish strain of the same $O$ group (similarity 0.965 ; data not shown) that also produced VT but not HLY. Similarly, with four strains of serogroup $\mathbf{O} 44$ (phenotypes $\mathrm{B}_{1}$ and $\mathrm{B}_{2}$ ), another closely related strain not only belonged to the same $\mathrm{O}$ group but also showed LA.

Bacterial clones which exist for a long time in a given population may undergo changes in phenotypic characters, ${ }^{4}$ and lose virulence factors. ${ }^{11}$ We have reported previously that the biochemical phenotypes of EPEC strains may be more stable on subculture 


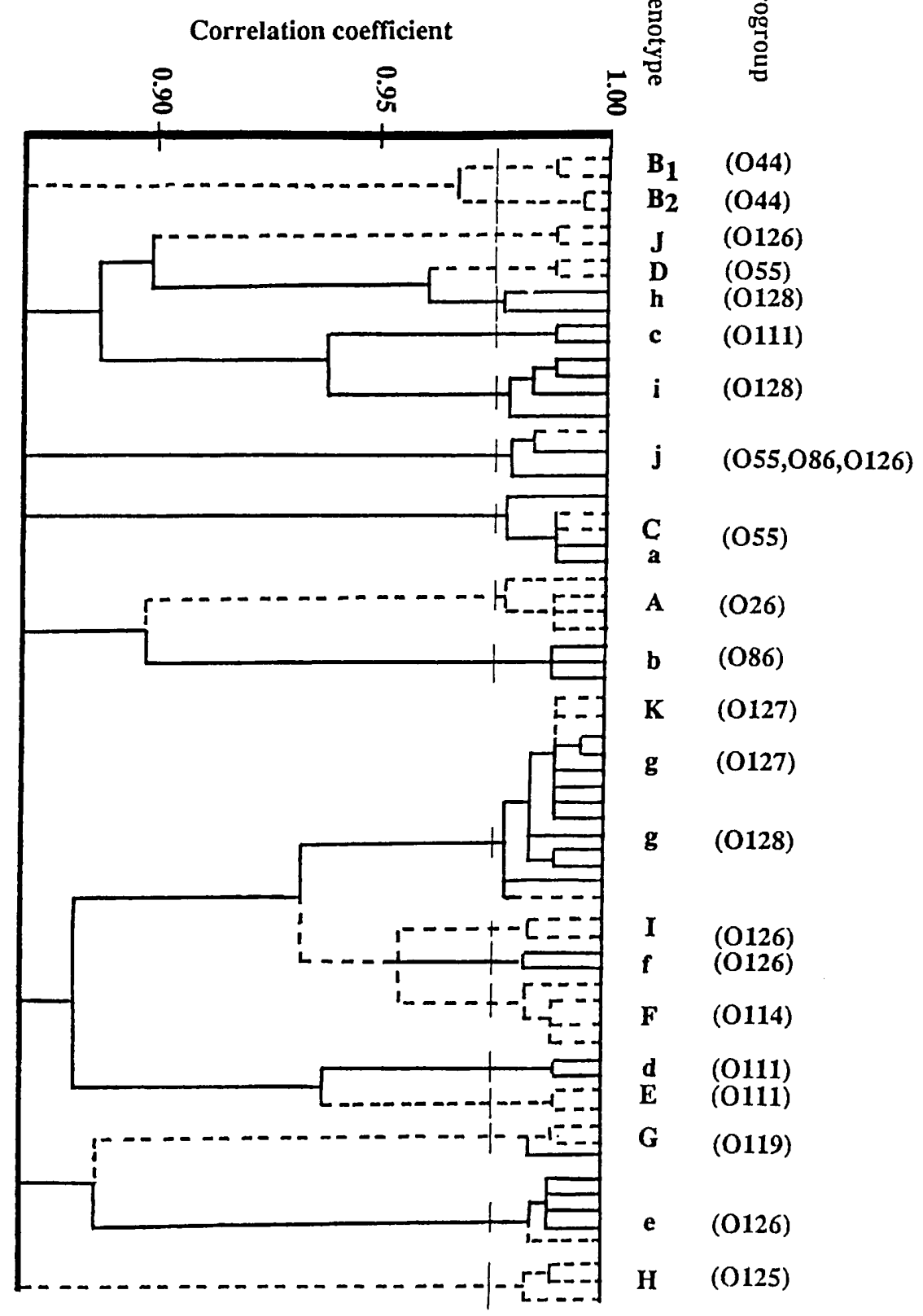

Figure. Dendrogram of 32 Swedish (--.-) and 35 Iranian (- ) strains of EPEC. Common biochemical phenotypes (C-phenotypes) are shown with capital letters for Swedish and small letters for Iranian strains. The discontinuous vertical line $(r=0 \cdot 975)$ indicates the chosen identity level for strains to be assigned to the same biochemical phenotype. This two-dimensional model produces some discrepancies: for example, the two Swedish 0127 isolates $(\mathrm{K})$ were phenotypically different from the single 0128 isolate $(\mathrm{r}<0.975)$, but all three showed phenotypic identity $(r>0 \cdot 975)$ with the similar cluster $(g)$ from Iran.

and storage than those of normal faecal E.coli strains. ${ }^{18}$ In contrast, most of the virulence factors of E. coli strains may be lost after such treatment. ${ }^{19-21}$ Therefore, it is possible that some strains of one biochemical phenotype, including closely related strains, might have lost some virulence factors during storage and would have appeared as not identical if only their virulence factors were evaluated. In our study, EAF and HLY were measured only once; this may explain small differences in virulence factors among the strains of each C-phenotype, as some variation in duplicate assays is to be expected.

Among Iranian isolates, $10 \mathrm{C}$-phenotypes, belong- ing to six different $O$ groups, were observed. Twelve strains of group $\mathrm{O} 128$ belonged to three different phenotypes ( $h$, $i$ and $g$; see table III). This serogroup has been shown previously to account for the majority of the EPEC strains isolated from diarrhoeal cases in Iran. ${ }^{22,23}$ Our present results show that three major and probably related phenotypes $\left(\overline{\mathrm{r}}_{1}=0.822\right)$ in this serogroup are particularly common in Iran, and infection by this serogroup is thus probably due to the spread of three clones. We also found one Swedish strain carrying this $O$ antigen and belonging to biochemical phenotype $\mathrm{g}$ (see figure).

Four Iranian strains of group O127, also, were of 
the same biochemical phenotype (type $\mathrm{g}$ ) as six strains of group O128, showing that strains of two different serogroups might be biochemically related. The clone concept has been defined as "bacterial cultures isolated independently from different sources, at different geographical areas and at different times, but showing so many identical phenotypes and genetic traits that the most likely explanation for this identity is a common origin". ${ }^{4}$ Nine Swedish and 20 Iranian isolates in this study showed biochemical identity to at least one of the strains of the other country and most of them (26 strains) also carried the same $O$ antigen. Furthermore, many of the strains within each C-phenotype had similar virulence factors (EAF, VT, HLY). In an analysis of OMP patterns of 129 strains of $E$. coli belonging to different serotypes of groups $\mathrm{O} 55$ and $\mathrm{O} 111$, isolated from geographically distinct areas, Stenderup and Ørskov ${ }^{5}$ found stable sero/bio/ OMP types, and concluded that such highly defined phenotypes represent bacterial clones that have been spread worldwide. The presence of common serogroups and phenotypes among the EPEC strains in our study confirms those results and the theories of widespread pathogenic clones.

$\mathrm{Kühn}^{8}$ showed that, with large numbers of randomly selected isolates of E. coli, mean homogeneities for biochemical phenotypes varied between 0.62 and 0.66 . If the homogeneity is higher, this indicates that some of the isolates may be related. In the present study, we found a high homogeneity among the strains of most $\mathrm{O}$ groups. However, five Swedish isolates of group O55 (two C-phenotypes and one S-phenotype) and three Iranian isolates of group O26 (three S-phenotypes) had very low homogeneity $(0.556$ and 0.579 respectively); this indicates that they belonged to totally unrelated clones which have spread in these countries.

\section{References}

1. Neter E. Enteritis due to enteropathogenic Escherichia coli: present-day status and undissolved problems. $J$ Pediatr $1959 ; 55$ : 223-239.

2. Robins-Browne RM. Traditional enteropathogenic Escherichia coli of infantile diarrhea. Rev Infect Dis 1987; 9: 28-53.

3. Czirók É, Ørskov I, Ørskov F. O:K:H:F serotypes of fimbriated Escherichia coli strains isolated from infants with diarrhea. Infect Immun 1982; 37: 519-525.

4. Ørskov F, Ørskov I. Summary of workshop on the clone concept in epidemiology, taxonomy, and evolution of the Enterobacteriaceae and other bacteria. J Infect Dis 1983; 148: 346-357.

5. Stenderup J, Ørskov F. The clonal nature of enteropathogenic Escherichia coli strains. J Infect Dis 1983; 148: 1019-1024.

6. Crichton PB, Old DC. A biotyping scheme for the subspecific discrimination of Escherichia coli. J Med Microbiol 1982; 15: $233-242$.

7. Brauner A, Boeufgras J-M, Jacobson SH et al. The use of biochemical markers, serotypes and fimbriation in the detection of Escherichia coli clones. J Gen Microbiol 1987; 133: 2825-2834.

8. Kühn I. Biochemical fingerprinting of Escherichia coli: a simple method for epidemiological investigations. J Microbiol Methods $1985 ; 3$ : $159-170$.
Three strains (Iranian C-phenotype $\mathrm{j}$ and one Swedish isolate) were found to belong to the same biochemical phenotype, but had three different $\mathrm{O}$ antigens. The reason is unclear. Because these strains had been tested originally with different sets of antisera, we re-tested them with both sets and obtained similar results.

Serotyping of $E$. coli strains has been considered to reveal uniform genetic entities and, therefore, meaningful units of the population structure. ${ }^{24,25}$ However, this view has been questioned. For instance, in an analysis of chromosomal-gene diversity by multilocus enzyme electrophoresis of 261 strains of $E$. coli with various $\mathrm{O}, \mathrm{K}$ and $\mathrm{H}$ antigens, Gaugant et al. ${ }^{26}$ found that most strains of the same electrophoretic type (ET) shared the same combination of antigens. However, some antigenic diversity was also observed among isolates of the same ET. Our results of biochemical fingerprinting of EPEC strains from Sweden and Iran showed that most of the isolates of the same biochemical phenotype carried the same $\mathrm{O}$ antigen. However, like the above workers, we also found that certain biochemical phenotypes (e.g., Iranian C-phenotype g) included isolates of different serogroups (O127 and O128). Nevertheless, the fact that some strains of each C-phenotype, within each serogroup, also had similar virulence factors supports the previous findings by Kühn et al. ${ }^{11}$ and Kühn and Möllby ${ }^{27}$ that the biochemical fingerprinting method described above, together with $\mathrm{O}$ antigen typing, could be an easy and useful method in identifying $E$. coli clones of diverse origin.

We thank Ms Gunnel Sigstam and Birgitta Karlsson for their skillful technical assistance. This study was supported financially by the Swedish Board for Agriculture and Forestry Research (grants $0584 / 89 \mathrm{~L} 139$ and 0777/89 D 326) and by the Karolinska Institute.

9. Kühn I, Brauner A, Möllby R. Evaluation of numerical typing systems for Escherichia coli using the API $50 \mathrm{CH}$ and the PhP-EC systems as models. Epidemiol Infect 1990; 105: 521-531.

10. Sneath PHA. Numerical taxonomy. San Francisco, W. H. Freeman. 1973.

11. Kühn I, Franklin A, Söderlind O, Möllby R. Phenotypic variations among enterotoxinogenic Escherichia coli from Swedish piglets with diarrhoea. Med Microbiol Immunol $1985 ; 174$ : 119-130.

12. Scaletsky ICA, Silva MLM, Trabulsi LR. Distinctive patterns of adherence of enteropathogenic Escherichia coli to HeLa cells. Infect Immun $1984 ;$ 45: 534-536.

13. Baloda SB, Yuk YR, Krovacek K, Sethi SK, Wadström T. Detection of Shiga-Like (SL) toxins of enteropathogenic Escherichia coli (EPEC) of human, porcine, calf and lamb origin on Vero and HeLa S3 cells: a comparative study. Zentralbl Bakteriol Mikrobiol Hyg A 1987; 264: 33-40.

14. Konowalchuk J, Speirs JI, Stavric S. Vero response to a cytotoxin of Escherichia coli. Infect Immun 1977; 18: 775779.

15. Achtman M, Mercer A, Kusecek B et al. Six widespread bacterial clones among Escherichia coli isolates. Infect Immun 1983; 39: 315-335.

16. Ochman H, Selander RK. Evidence for clonal population structure in Escherichia coli. Proc Natl Acad Sci USA 1984; 81: 198-201. 
17. Rennie RP, Nord CE, Sjoberg L, Duncan IBR. Comparison of bacteriophage typing, serotyping and biotyping as aids in epidemiological surveillance of Klebsiella infections. J Clin Microbiol $1978 ; 8$ : 638-642.

18. Katouli M, Kühn I, Möllby R. Evaluation of the stability of biochemical phenotypes of Escherichia coli upon subculturing and storage. J Gen Microbiol 1990; 136: 1681-1688.

19. Levine MM, Ristanio P, Sack RB, Kapper JB, Ørskov F Ørskov I. Colonization factor antigens I and II and type $I$ somatic pili in enterotoxigenic Escherichia coli: relation to enterotoxin type. Infect Immun 1983; 39: 889-897.

20. Evans DJ, Evans DG, DuPont HL, Ørskov F, Ørskov I. Patterns of loss of enterotoxigenicity by Escherichia coli isolated from adults with diarrhea: suggestive evidence for an interrelationship with serotype. Infect Immun 1977; 17: $105-111$.

21. Åhrén CM, Gothefors L, Stoll BJ, Salek MA, Svennerholm A$\mathrm{M}$. Comparison of methods for detection of colonization factor antigens on enterotoxigenic Escherichia coli. J Clin Microbiol 1986; 23: 586-591.
22. Katouli M, Jaafari A, Ketabi GR. The role of diarrhoeagenic Escherichia coli in acute diarrhoeal diseases in BandarAbbas, Iran. J Med Microbiol 1988; 27 : 71-74.

23. Katouli M, Jaafari A, Farhoudi-Moghaddam AA, Ketabi GR. Aetiological studies of diarrhoeal diseases in infants and young children in Iran. J Trop Med Hyg 1990; 93: 22-27.

24. Bettelheim KA. The sources of "OH" serotypes of Escherichia coli. J Hyg 1978; 80: 83-113.

25. Ørskov F, Ørskov I, Evans DJ, Sack RB, Sack DA, Wadström T. Special Escherichia coli serotypes among enterotoxigenic strains from diarrhea in adults and children. Med Microbiol 1976; 162: 73-80.

26. Gaugant DA, Levin BR, Ørskov I, Ørskov F, Svanborg Eden C, Selander RK. Genetic diversity in relation to serotype in Escherichia coli. Infect Immun 1985; 49: 407-413.

27. Kühn I, Möllby R. Phenotypic variations among enterotoxigenic O-groups of Escherichia coli from various human populations. Med Microbiol Immunol 1986; 175: 15-26. 